Article

\title{
Geographical Distribution of Borrelia burgdorferi sensu lato in Ticks Collected from Wild Rodents in the Republic of Korea
}

\author{
Seong Yoon Kim ${ }^{\circledR}$, Tae-Kyu Kim, Tae Yun Kim and Hee Il Lee * \\ Division of Vectors and Parasitic Diseases, Bureau of Infectious Disease Diagnosis Control, Korea Disease \\ Control and Prevention Agency, 187 Osongsaengmyeong 2-ro, Cheongwon-gun, Cheongju-si 363-951, \\ Chungcheongbuk-do 28159, Korea; gunbo0402@korea.kr (S.Y.K.); tkkim80@korea.kr (T.-K.K.); \\ kty4588@korea.kr (T.Y.K.) \\ * Correspondence: isak@korea.kr; Tel.: +82-43-719-8560; Fax: 82-43-719-8589
}

Received: 21 September 2020; Accepted: 22 October 2020; Published: 22 October 2020

\begin{abstract}
Lyme disease is a tick-borne zoonotic disease caused by Borrelia burgdorferi sensu lato (s. 1.) via transmission cycles involving competent tick vectors and vertebrate reservoirs. Here, we determined the prevalence and distribution of Borrelia genospecies in 738 ticks of at least three species from wild rodents in nine regions of the Republic of Korea (ROK). Ticks were analyzed using nested PCR targeting partial flagellin $B$ gene sequences, followed by sequence analysis. The prevalence of Borrelia infection was $33.6 \%$, and the most common genospecies were B. afzelii (62.5\%), B. valaisiana (31.9\%), B. yangtzensis (2.4\%), B. garinii (1.6\%), and B. tanukii (1.6\%). Borrelia afzelii was found in all regions except Jeju Island; this predominant genospecies was found in the northern and central sampling regions. Borrelia valaisiana, B. yangtzensis, and B. tanukii were found only in the southern regions with $B$. valaisiana being the most common, whereas $B$. yangtzensis and $B$. tanukii were only found on Jeju Island. Our study is the first to describe the nationwide prevalence of $B$. burgdorferi s. 1. in ticks from wild rodents in the ROK. Continuous surveillance in ticks, animals, humans, and different regions is required to avoid disease distribution and possible transmission to humans in the ROK.
\end{abstract}

Keywords: lyme disease; Borrelia burgdorferi sensu lato; tick; wild rodent

\section{Introduction}

Lyme disease (LD) is the most prevalent tick-borne zoonotic disease and is common in all temperate regions of the Northern Hemisphere, including Asia, Europe, America, Africa, and Oceania, with more than 0.3 million clinical cases per year [1]. Borrelia burgdorferi sensu lato (s. 1.) is the causative agent of LD and comprises of at least 20 different named and unnamed genospecies [2]. Three of these are the major causative agents of LD in humans and display different clinical manifestations and geographical distributions. For instance, B. afzelii and B. garinii are known to cause dermatitis and neuritis, respectively, in Eurasia, while B. burgdorferi sensu stricto (s. s) causes arthritis in the United States and Western Europe [3-5].

Borrelia burgdorferi sensu lato (s. 1.) is mainly maintained via transmission cycles involving competent tick vectors and vertebrate reservoirs [6]; therefore, ticks are used for epidemiological studies of tick-borne pathogens [7]. Ixodes ricinus is typically found in Europe, while I. scapularis and I. pacificus are found in North America, and I. persulcatus and I. nipponensis are found in Asia [4]. The larvae of hard ticks are uninfected due to the lack of transovarial transmission; however, B. burgdorferi $\mathrm{s}$. 1. is acquired by feeding on an infected animal reservoir. After molting to the next stage, the ticks can transmit 
the pathogen to animals such as small mammals, which are common hosts for immature ticks [2]. Since blood-sucking vectors contain infected host blood and the pathogen itself, they are reliable tools for demonstrating the existence of the pathogens in a specific area [7]. Moreover, micromammal species have been widely investigated because they act as natural reservoirs in the Borrelia transmission cycle [8].

Borrelia burgdorferi sensu lato (s. 1.) was first identified in the Republic of Korea (ROK) in Ixodes ticks and the wild rodent Apodemus agrarius in 1993, with the first human case of LD reported in the same year $[9,10]$. Lyme disease (LD) was designated as a national notifiable infectious disease in 2010, and two cases were identified in 2011. Since then, the number of cases has gradually increased; 23 cases have been reported in 2019, including 11 imported cases [11]. To date, various molecular and serological studies have identified the pathogenic cause of LD in ticks and animals including wild rodents, migratory birds, water deer, and dogs [12-20]. Borrelia afzelii and B. garinii were first identified in I. persulcatus and wild rodents, respectively, from the Gangwon province. Moreover, other genospecies of B. burgdorferi s. 1., including B. tanukii, B. turdi, B. yangtzensis, B. bavariensis, and $B$. valaisiana, have been identified in ticks and wild animals [9,16,18-22]. Regional information regarding ticks, wild animals, and $B$. burgdorferi s. 1 . genospecies has been revealed sporadically in the ROK; however, the main B. burgdorferi s. 1. genospecies and its prevalence within tick distributions remain unknown.

In this study, we aimed to determine the prevalence and distribution of Borrelia genospecies in ticks attached to wild rodents throughout ROK as part of a nationwide investigation.

\section{Results}

\subsection{Tick Samples and Infection Rates}

First, we examined Borrelia infection in engorged ticks attached to 123 wild rodents collected from nine regions. Apodemus agrarius (90.2\%) was the predominant rodent species, followed by Crocidura lasiura (8.9\%) and Craseomys regulus (0.8\%; data not shown). A total of 738 engorged ticks were collected that included ticks from two genera and at least three species. Some Ixodes spp. cannot be identified in their larval stage so we used the term "Ixodes spp." to refer to these ticks (Table 1). Ixodes nipponensis, I. angustus, and H. longicornis were collected from wild rodents and examined individually. Overall, 33.6\% (248 positive ticks among the 738 ticks examined) of the ticks tested positive via PCR, including $56.5 \%$ of I. nipponensis, $30.7 \%$ of Ixodes spp., $11.1 \%$ of H. longicornis, and $3.1 \%$ of I. angustus (Table 1).

Table 1. Prevalence of Borrelia genospecies in engorged ticks via nested PCR for flaB.

\begin{tabular}{|c|c|c|c|c|c|c|c|c|c|}
\hline Species & Stage & $\begin{array}{l}\text { No. of } \\
\text { Ticks }\end{array}$ & \multicolumn{2}{|c|}{ Positive (\%) } & \multicolumn{5}{|c|}{ Borrelia Genospecies } \\
\hline Ixodes spp. & larva & 440 & 135 & $(30.7)$ & 102 & 1 & 29 & 3 & 0 \\
\hline I. nipponensis & nymph & 193 & 109 & $(56.5)$ & 53 & 3 & 50 & 2 & 1 \\
\hline \multirow{2}{*}{ I. angustus } & larva & 78 & 2 & (2.6) & 0 & 0 & 0 & 0 & 2 \\
\hline & nymph & 18 & 1 & (5.6) & 0 & 0 & 0 & 0 & 1 \\
\hline Total & & 738 & 248 & $(33.6)$ & 155 & 4 & 79 & 6 & 4 \\
\hline
\end{tabular}

\subsection{Molecular Identification of B. burgdorferi s. $l$.}

A total of five B. burgdorferi s. 1. genospecies were identified, of which the most common genospecies were B. afzelii (62.5\%), followed by B. valaisiana (31.9\%), B. yangtzensis (2.4\%), B. garinii $(1.6 \%)$, and B. tanukii (1.6\%; Table 1). In the regional distribution, B. afzelii was found in all the inland sampling regions except for Jeju Island, while Sejong and Uiseong located in the central inland regions 
only identified B. afzelii. Borrelia valaisiana was found in Geoje, Goheung, and Jeju Island, which are located in the southern sampling regions, and displayed a higher prevalence than other genospecies. Specifically, B. yangtzensis and B. tanukii were only found on Jeju Island (Figure 1).

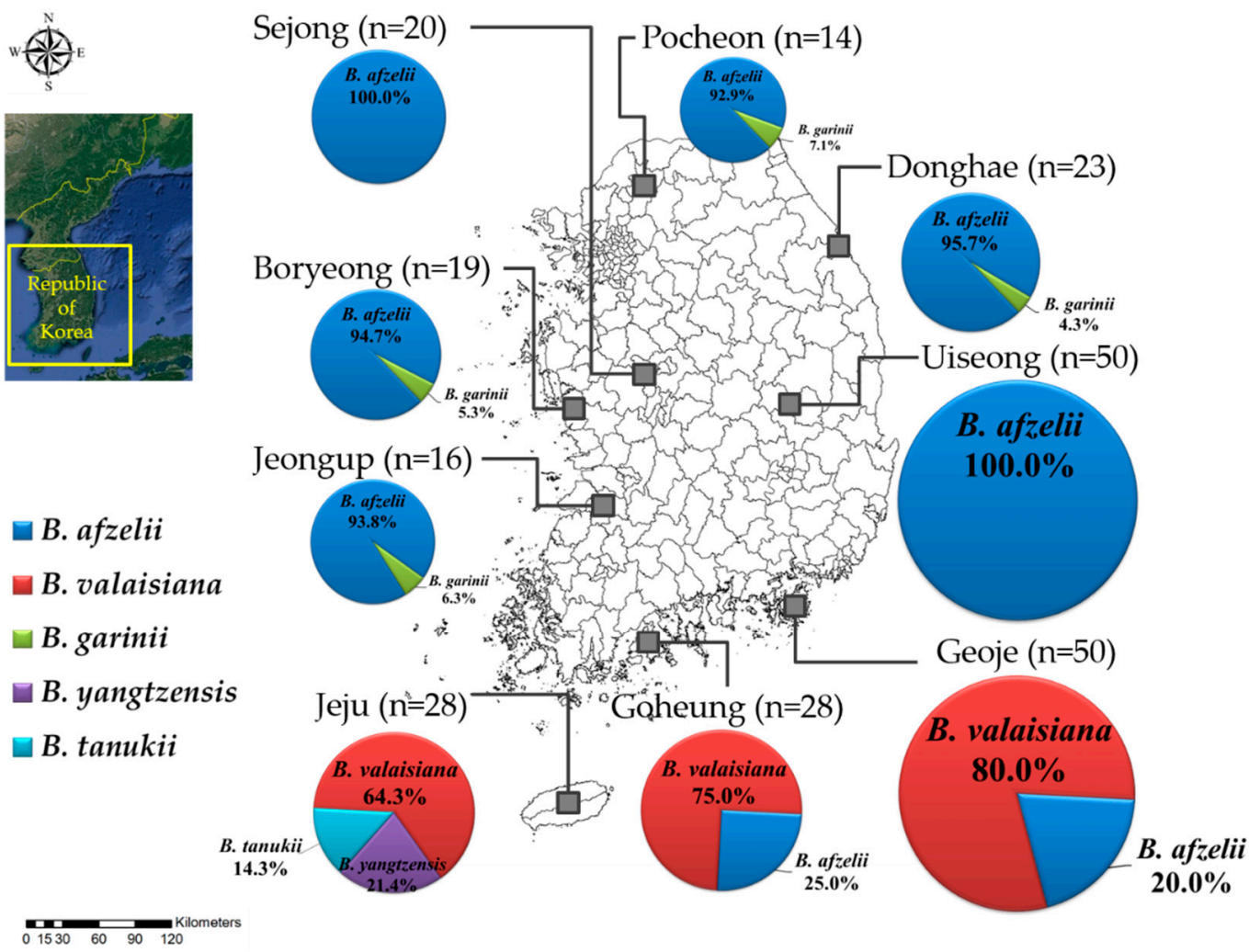

Figure 1. A map of the Borrelia genospecies detected in the different sampling regions of the ROK.

\subsection{Phylogenetic Tree of B. burgdorferi s. l.}

We selected 24 representative samples without duplicate sequences among the 248 ticks identified as positive for Borrelia genospecies and constructed a phylogenetic tree using the flagellin B (flaB) genes from several Borrelia genospecies sequences deposited in GenBank (Figure 2). The representative sequences of the five genospecies clustered with related reference sequences; however, $B$. yangtzensis clustered together in a large clade closely related to B. valaisiana. No apparent clustering was observed based on the tick host or sampling region. 


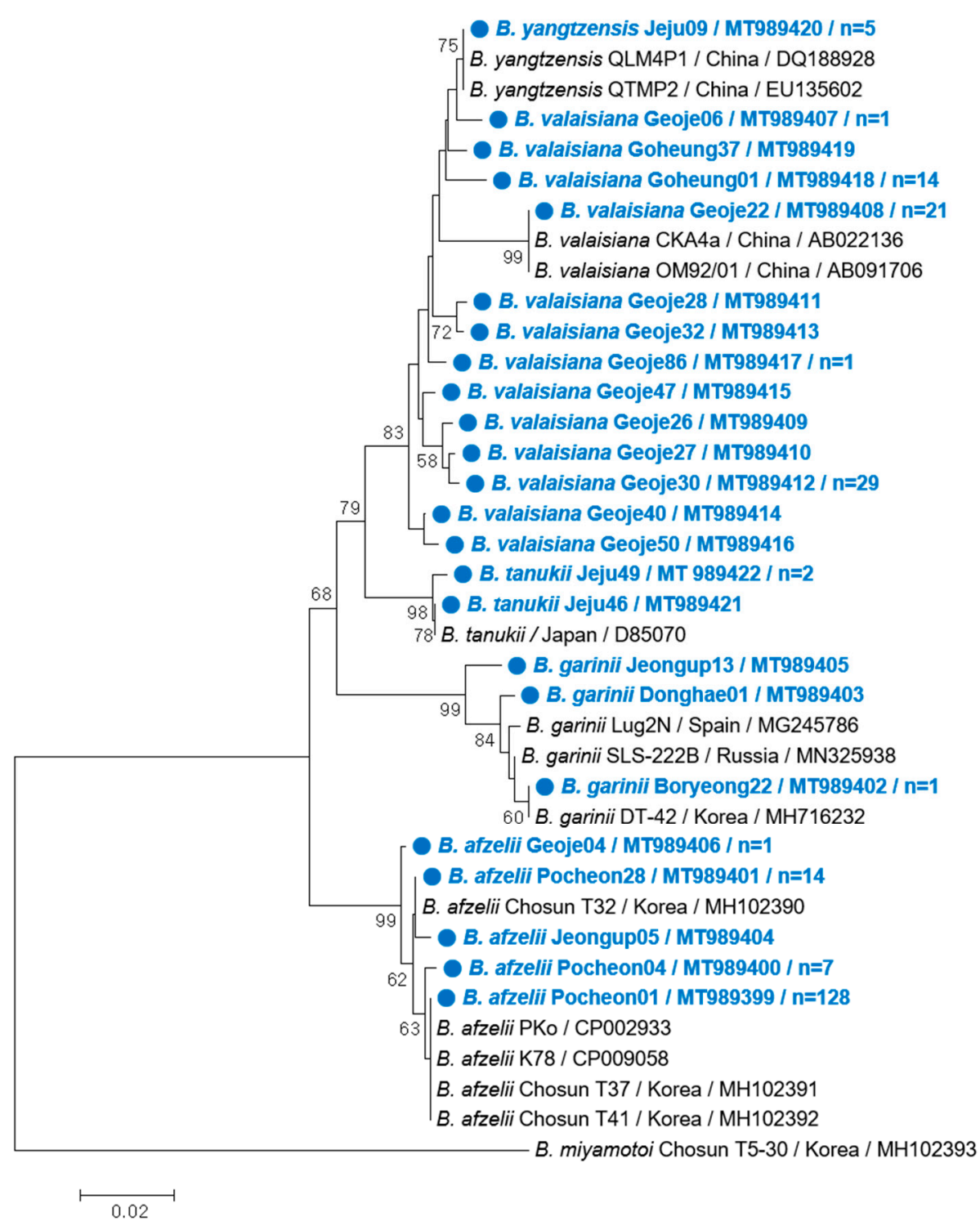

Figure 2. Phylogenetic relationship between Borrelia genospecies based on partial flaB nucleotide sequences (303 nucleotide positions) constructed using the neighbor-joining method in MEGA 5.2. Node numbers indicate the proportion of bootstrap replicates (1000) that supported the topology shown. The cutoff value for the consensus tree was $50 \%$. The scale bar represents $2 \%$ divergence. The sequences identified in this study are indicated by blue circles. The number of sequences $(n)$ with an identical genospecies are shown if the sequence was detected in more than one case.

\section{Discussion}

In this study, we performed the molecular detection and phylogenetic analysis of B. burgdorferi s. 1 . in engorged ticks from wild rodents in nine regions of the ROK. Nested PCR revealed an overall Borrelia infection rate of $33.6 \%$ among the 738 ticks analyzed, similar to the high prevalence rates found in ticks feeding on wild rodents in Malaysia (46.1\%) and Taiwan (47.1\%) [23,24]. However, previous studies from the ROK have detected very low rates of B. burgdorferi s. 1 . in ticks feeding on wild animals such as dogs $(0.2 \%, n=562$ ticks) [20], wild water deer (2.1\%, $n=48$ ticks) [19], migratory birds (3.7\%, four positive pools of 108 tested pools among 212 ticks) [18], and wild rodents in northern Gyeonggi near the demilitarized zone $(1.0 \%, n=1618$ ticks including 933 questing ticks) [25]. These differences in prevalence may be due to variations in the sampling methods for tick and host species, survey regions, the environment, and the seasonal timing of the survey. 
Sequence analysis, including phylogenetic analysis based on partial flaB sequences, confirmed that B. afzelii, B. valaisiana, B. garinii, B. yangtzensis, and B. tanukii, were detected in the ticks collected in this study and displayed isolated geographical distribution. For instance, B. afzelii and B. garinii were found only inland, while $B$. afzelii was the main genospecies in the northern and central sampling regions. Conversely, B. valaisiana, B. yangtzensis, and B. tanukii were only found in the southern sampling regions, where $B$. valaisiana was the most common genospecies. Previous studies in the ROK have identified B. afzelii and B. garinii in various tick species, animals, and patient sera throughout inland areas $[9,16,19-22,26]$. In addition, other B. burgdorferi s. 1. groups, such as $B$. valaisiana, have been detected in I. nipponensis [27], whereas B. yangtzensis was reclassified via multilocus sequence typing in A. agrarius from Haenam in the southernmost inland region [22]. Borrelia tanukii has been reported in Ixodes tanuki from Japan [28]. In the ROK, a similar partial 16s rRNA sequence of $B$. tanukii has been reported in ticks feeding on migratory birds on Hongdo Island [18]; however, it was unclear whether the ticks were indigenous. Our study demonstrates for the first time that $B$. tanukii is indigenous to ticks in the ROK. Many B. burgdorferi s. 1. genospecies, including B. afzelii, B. garinii, B. burgdorferi s. s., B. bavariensis, and B. bissettii, are known to be pathogenic to humans, while B. lusitaniae, B. spielmanii, and B. valaisiana are considered potentially pathogenic [3]. In this study, the identification of B. afzelii and B. valaisiana in ticks that act as major Borrelia vectors indicates that $L D$ transmission may be possible via questing ticks in the ROK.

A previous study in which vegetation was swept and dragged for questing ticks identified $H$. longicornis and H. flava as the dominant tick species, while I. nipponensis has been shown to be the most frequently collected tick from small mammals [29,30]. Our study found that most of the ticks collected from wild rodents were of the Ixodes genus, including Ixodes spp. ( $n=440,59.6 \%)$, I. nipponensis ( $n=193,26.1 \%)$, and I. angustus ( $n=96,13.0 \%)$. Moreover, we found that Borrelia DNA was prevalent in I. nipponensis, Ixodes spp., I. angustus, and H. longicornis; however, the prevalence varied between species. Borrelia burgdorferi sensu lato (s. 1.) was first identified from I. angustus in the ROK and has since been found in several other tick species, such as I. granulatus, I. persulcatus, I. nipponensis, I. turdus, and H. longicornis $[9,18,19,27]$. In experimental vector competence studies, I. angustus was found to be a competent vector for transmitting $B$. burgdorferi s. s. to deer mice [31], while this study identified Borrelia infection in 1/9 H. longicornis larvae. A previous study reported the first molecular detection of B. afzelii in H. longicornis infesting wild Korean water deer (Hydropotes inermis) in the ROK [19]; however, Sun et al. [32] showed that H. longicornis can carry but not transmit Borrelia as H. longicornis can only maintain spirochetes for a shorter period than the digestion period of blood. Therefore, H. longicornis is not the main Borrelia vector, despite being dominant in the ROK, indicating that Ixodes species may be the main vector and carrier of Borrelia in the ROK. Because we used ticks harvested from wild rodents, the Borrelia genospecies and infection rate in this study may have originated from the wild rodent itself. Nevertheless, blood-sucking vectors are reliable tools for demonstrating the existence of pathogens in a specific area [7]. Human biting cases by the Ixodes species was significantly lower (5.7\%) than those by other species in the ROK [33]. Considering the gradually increasing number of LD cases in the ROK and the high Borrelia infection rate in ticks engorged with wild rodent blood in this study, monitoring for Borrelia in non-engorged or questing ticks at different developmental stages should be carried out.

To our knowledge, this study is the first to describe the nationwide prevalence of B. burgdorferi s. 1 . in engorged ticks from wild rodents in the ROK. The ticks were found to have a high infection rate $(33.6 \%)$ and a wide geographical distribution for the five detected genospecies of B. burgdorferi s. 1., the causative agent of LD. Humans working in agricultural fields, visiting mountains and reservoirs for recreational activities, or inhabiting residential areas may therefore be at risk of exposure to and infection with Borrelia due to close contact with wild rodents and ticks. Thus, continuous surveillance on various tick species, animals, humans, and different geographical regions is required to reduce disease distribution and possible transmission to humans in the ROK. 


\section{Materials and Methods}

\subsection{Surveillance Localities and Periods}

Ticks were collected from wild rodents during spring (March-May) and autumn (September-November) in 2017 from nine regions in the ROK, namely Pocheon, Donghae, Sejong, Boryeong, Uiseong, Jeongup, Geoje, Goheung, and Jeju Island (Figure 1). Rodent traps were installed at several environmental sites, including cropped fields, reservoirs, waterways, and mountains. The animal-handling protocol used in this study was reviewed and approved based on the guidelines for ethical procedures and scientific care of the Institutional Animal Care and Use Committee of the Korea Centers for Disease Control and Prevention (KCDC-089-17).

\subsection{Collection of Wild Rodents and Ticks}

At each site, 25 Sherman folding live traps $(3 \times 3.5 \times 9$ inches, BioQuip, Gardena, CA, USA) were set up at five points at 3-5 m intervals with a peanut butter-spread biscuit. The rodent traps were collected the next morning and transported to the laboratory. After euthanization using compressed carbon dioxide, the rodents were suspended for $24 \mathrm{~h}$ over glass bowls filled with $70 \% \mathrm{EtOH}$ to collect ticks. The ticks were then recovered from the surface using a fine brush and stored in $70 \% \mathrm{EtOH}$ at $-20{ }^{\circ} \mathrm{C}$ for identification.

\subsection{Identification of Ticks}

The species and developmental stage of each tick were identified under a dissection microscope using taxonomic identification keys according to Yamaguti et al. (1971) [34]. Individual ticks were then placed in a $2 \mathrm{~mL}$ screw cap tube according to the host rodent, collection site, region, and season and were stored at $-20{ }^{\circ} \mathrm{C}$ before DNA extraction.

\subsection{Detection of Borrelia DNA in Ticks}

Tick samples were homogenized in $450 \mu \mathrm{L}$ of $1 \times$ phosphate-buffered saline (PBS) with $2.8 \mathrm{~mm}$ ceramic (zirconium oxide) beads using a Precellys Evolution homogenizer (Bertin Technologies, Bretonneux, France). The homogenates were centrifuged at 25,000 $\mathrm{g}$ for $10 \mathrm{~min}$, and $400 \mu \mathrm{L}$ of the supernatant was used for DNA extraction using a MagMAX ${ }^{\mathrm{TM}}$ DNA Multi-Sample Ultra 2.0 Kit (Applied Biosystems, Foster city, CA, USA) according to the manufacturer's instructions. To detect Borrelia DNA in tick samples, we targeted a partial flaB sequence, as described previously [34] (Table 2). For the first PCR reaction, $5 \mu \mathrm{L}$ of tick template DNA was added to AccuPower ${ }^{\circledR}$ HotStart PCR PreMix (Bioneer, Daejeon, Korea) and incubated at $94{ }^{\circ} \mathrm{C}$ for $5 \mathrm{~min}$, followed by 35 cycles of $94{ }^{\circ} \mathrm{C}$ for $30 \mathrm{~s}$, $60{ }^{\circ} \mathrm{C}$ for $45 \mathrm{~s}$, and $72{ }^{\circ} \mathrm{C}$ for $1 \mathrm{~min}$, with a final amplification at $72{ }^{\circ} \mathrm{C}$ for $10 \mathrm{~min}$. Secondary nested PCR was then performed using $1 \mu \mathrm{L}$ of the primary PCR products under the following conditions: $94{ }^{\circ} \mathrm{C}$ for $5 \mathrm{~min}$, followed by 25 cycles of $94^{\circ} \mathrm{C}$ for $10 \mathrm{~s}, 48{ }^{\circ} \mathrm{C}$ for $1 \mathrm{~min}, 72{ }^{\circ} \mathrm{C}$ for $90 \mathrm{~s}$, and a final extension step at $72{ }^{\circ} \mathrm{C}$ for $5 \mathrm{~min}$. Positive and negative controls were included in each PCR set. Amplified PCR products were visualized via 2.0\% agarose gel electrophoresis after staining with Safe-Pinky DNA Gel Staining Solution (10,000×) in water (GenDEPOT, Barker, TX, USA), yielding a predicted size of 347 bp. To avoid cross-contamination, DNA extraction, amplification, and agarose gel electrophoresis were performed in separate rooms.

Table 2. DNA sequences of primers used for nested PCR.

\begin{tabular}{|c|c|c|c|c|c|}
\hline $\begin{array}{c}\text { Targe } \\
\text { Specificity }\end{array}$ & Designation & & Sequence & $\begin{array}{l}\text { Amplicon } \\
\text { Length (bp) }\end{array}$ & Reference \\
\hline \multirow{4}{*}{ Flagellin B } & BflaPAD & 1st & 5'-GATCARGCWCAAYATAACCAWATGCA-3' & & \multirow{4}{*}{ [35] } \\
\hline & BflaPDU & PCR & 5'-AGATTCAAGTCTGTTTTGGAAAGC-3' & 459 & \\
\hline & BflaPBU & 2nd & 5'-GCTGAAGAGCTTGGAATGCAACC-3' & \multirow{2}{*}{347} & \\
\hline & BflaPCR & PCR & 5'-TGATCAGTTATCATTCTAATAGCA-3' & & \\
\hline
\end{tabular}




\subsection{Sequencing and Phylogenetic Analysis}

All positive nested PCR products were sequenced in directions, using the PCR primers at Bioneer Inc. (Daejeon, ROK). To identify Borrelia genospecies, the sequencing results were analyzed using the BlastN program from the National Center for Biotechnology Information (NCBI, Bethesda, MD, USA). The sequences obtained in this study were aligned using CLUSTALW and compared to published sequences in GenBank (NIH, Montgomery, MD, USA). A phylogenetic tree was constructed based on the DNA sequences of flaB from tick samples with a Borrelia infection using the neighbor-joining method with the p-distance model in MEGA version 5.2. Bootstrap analysis was conducted using 1000 replicates to improve the confidence level of the phylogenetic tree. The GenBank accession numbers of the genospecies sequences obtained in this study are presented in Figure 2.

Author Contributions: Formal Analysis, T.Y.K.; Investigation, S.Y.K. and T.-K.K.; Resources, T.-K.K.; Data Curation and Writing-Original Draft Preparation, S.Y.K.; Conceptualization, Writing-Review \& Editing, and Funding Acquisition, H.I.L. All authors have read and agreed to the published version of the manuscript.

Funding: This study was financially supported by the Korea Centers for Disease Control and Prevention (Grant No. 2016-NG55001-00).

Acknowledgments: We thank Su Yeon Kim from the Division of Pathogen Resource Management and the Division of Bacterial Disease Research at the National Institute of Infectious Diseases for their technical expertise and help with the positive control in this study. We also thank the fieldwork crew, Bong Gu Song, Hak Seon Lee, Gi Hun Kim, Won Il Park, and Hyung Woo Lim, for their hard work and thoughtful contributions to the project. Lastly, this paper is dedicated to the memory of our friend and colleague, Jong Yul Roh, who passed away in May 2020 after helping us initiate and organize this project.

Conflicts of Interest: The authors declare no conflict of interest.

\section{References}

1. Aucott, J.; Morrison, C.; Munoz, B.; Rowe, P.C.; Schwarzwalder, A.; West, S.K. Diagnostic challenges of early Lyme disease: Lessons from a community case series. BMC Infect. Dis. 2009, 9, 79. [CrossRef] [PubMed]

2. Radolf, J.D.; Caimano, M.J.; Stevenson, B.; Hu, L.T. Of ticks, mice and men: Understanding the dual-host lifestyle of Lyme disease spirochaetes. Nat. Rev. Microbiol. 2012, 10, 87-99. [CrossRef] [PubMed]

3. Rudenko, N.; Golovchenko, M.; Grubhoffer, L.; Oliver, J.H., Jr. Updates on Borrelia burgdorferi sensu lato complex with respect to public health. Ticks Tick Borne Dis. 2011, 2, 123-128. [CrossRef] [PubMed]

4. Radolf, J.D.; Samuels, D.S. Borrelia: Molecular biology, host interaction and pathogenesis. Clin. Infect. Dis. 2011, 52, 965. [CrossRef]

5. Wang, G.; van Dam, A.P.; Schwartz, I.; Dankert, J. Molecular typing of Borrelia burgdorferi sensu lato: Taxonomic, epidemiological, and clinical implications. Clin. Microbiol. Rev. 1999, 12, 633-653. [CrossRef]

6. Hengge, U.R.; Tannapfel, A.; Tyring, S.K.; Erbel, R.; Arendt, G.; Ruzicka, T. Lyme borreliosis. Lancet Infect. Dis. 2003, 3, 489-500. [CrossRef]

7. Sparagano, O.A.; Allsopp, M.T.; Mank, R.A.; Rijpkema, S.G.; Figueroa, J.V.; Jongejan, F. Molecular detection of pathogen DNA in ticks (Acari: Ixodidae): A review. Exp. Appl. Acarol. 1999, 23, 929-960. [CrossRef]

8. Gern, L.; Humair, P.-F. Ecology of Borrelia burgdorferi sensu lato in Europe. In Lyme Borreliosis: Biology, Epidemiology and Control, 1st ed.; Gray, J., Kahl, O., Lane, R.S., Stanek, G., Eds.; CABI: Wallingford, UK, 2002; pp. 149-174.

9. Park, K.H.; Chang, W.H.; Schwan, T.G. Identification and characterization of Lyme disease spirochetes, Borrelia burgdorferi sensu lato, isolated in Korea. J. Clin. Microbiol. 1993, 31, 1831-1837. [CrossRef]

10. Lee, M.G.; Chung, K.Y.; Choi, Y.S.; Cho, S.N. Lyme disease. Korean, J. Dermatol. 1993, 31, 601-605. [CrossRef]

11. Korea Centers for Disease Control and Prevention (KCDC). Diseases Web Statistics System. Available online: http://www.cdc.go.kr/npt/biz/npp/ist/bass/bassAreaStatsMain.do (accessed on 15 July 2020).

12. Park, S.H.; Hwang, K.J.; Chu, H.; Park, M.Y. Serological detection of Lyme borreliosis agents in patients from Korea, 2005-2009. Osong Public Health Res. Perspect. 2011, 2, 29-33. [CrossRef]

13. Moon, S.; Hong, Y.; Hwang, K.J.; Kim, S.; Eom, J.; Kwon, D.; Park, J.H.; Youn, S.K.; Sohn, A. Epidemiological features and clinical manifestations of Lyme borreliosis in Korea during the period 2005-2012. Jpn. J. Infect. Dis. 2015, 68, 1-4. [CrossRef] [PubMed] 
14. Bell, D.R.; Berghaus, R.D.; Patel, S.; Beavers, S.; Fernandez, I.; Sanchez, S. Seroprevalence of tick-borne infections in military working dogs in the Republic of Korea. Vector Borne Zoonotic Dis. 2012, 12, 1023-1030. [CrossRef] [PubMed]

15. Lee, S.H.; Yun, S.H.; Choi, E.; Park, Y.S.; Lee, S.E.; Cho, G.J.; Kwon, O.D.; Kwak, D. Serological Detection of Borrelia burgdorferi among Horses in Korea. Korean J. Parasitol. 2016, 54, 97-101. [CrossRef] [PubMed]

16. Kee, S.; Hwang, K.-J.; Oh, H.-B.; Park, K.-S. Identification of Borrelia burgdorferi isolated in Korea using outer surface protein A (OspA) serotyping system. Microbiol. Immunol. 1994, 38, 989-993. [CrossRef]

17. Choi, Y.J.; Han, S.H.; Park, J.M.; Lee, K.M.; Lee, E.M.; Lee, S.H.; Song, H.J.; Koh, Y.S.; Lee, K.W.; Jang, W.J.; et al. First molecular detection of Borrelia afzelii in clinical samples in Korea. Microbiol. Immunol. 2007, 51, 1201-1207. [CrossRef]

18. Kang, J.G.; Kim, H.C.; Choi, C.Y.; Nam, H.Y.; Chae, H.Y.; Chong, S.T.; Klein, T.A.; Ko, S.; Chae, J.S. Molecular detection of Anaplasma, Bartonella, and Borrelia species in ticks collected from migratory birds from Hong-do Island, Republic of Korea. Vector Borne Zoonotic Dis. 2013, 13, 215-225. [CrossRef]

19. VanBik, D.; Lee, S.H.; Seo, M.G.; Jeon, B.R.; Goo, Y.K.; Park, S.J.; Rhee, M.H.; Kwon, O.D.; Kim, T.H.; Geraldino, P.J.L.; et al. Borrelia species detected in ticks feeding on wild Korean water deer (Hydropotes inermis) using molecular and genotypic analyses. J. Med. Entomol. 2017, 54, 1397-1402. [CrossRef]

20. Lee, S.H.; Goo, Y.K.; Geraldino, P.J.L.; Kwon, O.D.; Kwak, D. Molecular detection and characterization of Borrelia garinii (Spirochaetales: Borreliaceae) in Ixodes nipponensis (Ixodida: Ixodidae) parasitizing a dog in Korea. Pathogens 2019, 8, 289. [CrossRef]

21. Lee, S.H.; Jung, K.D.; Lee, J.H.; Kim, S.C.; Kim, J.H.; Jang, W.J.; Park, K.H. Characterization of Borrelia afzelii isolated from Ixodes nipponensis and Apodemus agrarius in Chungju, Korea, by PCR-rFLP analyses of ospC gene and rrf (5S)-rrl (23S) intergenic spacer. Microbiol. Immunol. 2002, 46, 677-683. [CrossRef]

22. Park, K.H.; Choi, Y.J.; Kim, J.; Park, H.J.; Song, D.; Jang, W.J. Reclassification of Borrelia spp. isolated in South Korea using multilocus sequence typing. Jpn. J. Infect. Dis. 2018, 71, 350-353. [CrossRef]

23. Khoo, J.J.; Ishak, S.N.; Lim, F.S.; Mohd-Taib, F.S.; Khor, C.S.; Loong, S.K.; AbuBakar, S. Detection of a Borrelia sp. from Ixodes granulatus ticks collected from rodents in Malaysia. J. Med. Entomol. 2018, 55, 1642-1647. [CrossRef] [PubMed]

24. Chao, L.L.; Liu, L.L.; Shih, C.M. Prevalence and molecular identification of Borrelia spirochetes in Ixodes granulatus ticks collected from Rattus losea on Kinmen Island of Taiwan. Parasit. Vectors 2012, 5, 167. [CrossRef] [PubMed]

25. Chae, J.S.; Yu, D.H.; Shringi, S.; Klein, T.A.; Kim, H.C.; Chong, S.T.; Lee, I.Y.; Foley, J. Microbial pathogens in ticks, rodents and a shrew in northern Gyeonggi-do near the DMZ, Korea. J. Vet. Sci. 2008, 9, 285-293. [CrossRef] [PubMed]

26. Lim, S.; Irwin, P.J.; Lee, S.; Oh, M.; Ahn, K.; Myung, B.; Shin, S. Comparison of selected canine vector-borne diseases between urban animal shelter and rural hunting dogs in Korea. Parasit. Vectors 2010, 3, 32. [CrossRef]

27. Masuzawa, T.; Fukui, T.; Miyake, M.; Oh, H.-B.; Cho, M.-K.; Chang, W.-H.; Imai, Y.; Yanagihara, Y. Determination of members of a Borrelia afzelii-related group isolated from Ixodes nipponensis in Korea as Borrelia valaisiana. Int. J. Syst. Bacteriol. 1999, 49, 1409-1415. [CrossRef]

28. Fukunaga, M.; Hamase, A.; Okada, K.; Nakao, M. Borrelia tanukii Sp. Nov. and Borrelia turdae Sp. Nov. found from Ixodid ticks in Japan. Microbiol. Immunol. 1996, 40, 877-881. [CrossRef]

29. Kim, H.C.; Kim, J.H.; Jo, Y.S.; Chong, S.T.; Sames, W.J.; Klein, T.A.; Robbins, R.G. Records of Ixodes pomeranzevi Serdyukova, 1941 (Acari: Ixodidae) from small mammals in northern Gyeonggi and Gangwon provinces, Republic of Korea. Syst. Appl. Acarol. 2009, 14, 129-135. [CrossRef]

30. Kim, H.C.; Chong, S.T.; Sames, W.J.; Nunn, P.V.; Wolf, S.P.; Robbins, R.G.; Klein, T.A. Tick surveillance of small mammals captured in Gyeonggi and Gangwon Provinces, Republic of Korea, 2004-2008. Syst. Appl. Acarol. 2010, 15, 100-108. [CrossRef]

31. Peavey, C.A.; Lane, R.S.; Damrow, T. Vector competence of Ixodes angustus (Acari: Ixodidae) for Borrelia burgdorferi sensu stricto. Exp. Appl. Acarol. 2000, 24, 77-84. [CrossRef]

32. Sun, Y.; Xu, R.M.; Guo, T.Y.; Zhang, P.H.; Cao, W.C. Incapability of Haemaphysalis longicornis and Dermacentor nuttalli to acquire and trans-stadial transmit the Lyme spirochetes Borrelia garinii. Acta Parasitol. Med. Entomol. Sin. 2003, 10, 174-180. 
33. Yun, S.M.; Lee, W.G.; Ryou, J.; Yang, S.C.; Park, S.W.; Roh, J.Y.; Lee, Y.-J.; Park, C.; Han, M.G. Severe fever with thrombocytopenia syndrome virus in ticks collected from humans, South Korea, 2013. Emerg. Infect. Dis. 2014, 20, 1358-1361. [CrossRef] [PubMed]

34. Yamaguti, N.; Tipton, V.J.; Keegan, H.L.; Toshioka, S. Ticks of Japan, Korea, and the Ryukyu islands. Brigham Young Univ. Sci. Bull. Biol. Ser. 1971, 15, 1.

35. Sato, Y.; Konishi, T.; Hashimoto, Y.; Takahashi, H.; Nakaya, K.; Fukunaga, M.; Nakao, M. Rapid diagnosis of lyme disease: Flagellin gene-based nested polymerase chain reaction for identification of causative Borrelia species. Int. J. Infect. Dis. 1997, 2, 64-73. [CrossRef]

Publisher's Note: MDPI stays neutral with regard to jurisdictional claims in published maps and institutional affiliations.

(C) 2020 by the authors. Licensee MDPI, Basel, Switzerland. This article is an open access article distributed under the terms and conditions of the Creative Commons Attribution (CC BY) license (http://creativecommons.org/licenses/by/4.0/). 